\title{
Review on Epidemiological Aspects and Economic Impact of Lumpy Skin Disease
}

\author{
Abeya Amenu*, Feyisa Bekuma, Gezali Abafaji and Derej Abera \\ College of Medical and Health Science, Wollega University, Ethiopia
}

Submission: August 09, 2018; Published: August 24, 2018

*Corresponding author: Abeya Amenu, school of Veterinary Medicine, Wollega University,Ethiopia. P.O. Box, 395. Tel no: +251-911-00-14-54; Email: fhodvm2@gmail.com

\begin{abstract}
Lumpy skin disease (LSD) is an acute infectious disease of cattle which is endemic in all most all African countries. It is economically devastating viral diseases which cause several financial problems in livestock industries because of significant milk yield loss, infertility, abortion and death. It is caused by lumpy skin diseases virus of capripoxvirus. The disease is characterized by fever, enlarged lymph nodes, firm, and circumscribed nodules in the skin and ulcerative lesions. It occurs in all agro climatic conditions but common in particularly in low lying areas and along watercourses. It is transmitted by insect vectors among the cattle sharing similar grazing and watering areas and those congregate in the same barn. Good understanding of epidemiology, economic significance and control mechanisms of the disease enable to design suitable control measures. Effective control measure of the disease is achieved through mass vaccination though separation and culling of infected animals.

Keywords: Economic Impact; Epidemiology; LSD; Transmission; Livestock; Arthropods; Pseudo urticaria; Polymerase Chain; Epidemiology; Histopathology; Epizootic; Enzyme; Lachrymal secretions; Etiology; Cutaneous lesions; Saliva; Nasal discharge; Feeding; Capripoxvirus

Abbreviations: LSD: Lumpy skin disease; LSDV: Lumpy skin disease Virus; PCR: Polymerase Chain Reaction; OIE: Office International des Epizootic; ELISA: Enzyme-linked immune sorbent assay
\end{abstract}

\section{Introduction}

Livestock production is an integral part of the agricultural system in Ethiopia. The livestock sub sector accounts for $40 \%$ of the agricultural and $20 \%$ of the total GDP without considering other contribution like traction power, fertilizing and mean of transport [1]. Ethiopia has an estimated 53.4 million (55.2\% are female and $44.8 \%$ are males) cattle distributed within the different agro-ecological zones [2]. About 99\% of cattle populations are of local Zebu breed. The remaining 1\% of exotic breeds is kept mainly for dairy production in and around urban areas [3]. Most of the cattle population is found in the highlands of Ethiopia where $43.6 \%$ of the human agricultural population is residing which indicates that cattle have a very important role in the Ethiopian economy [4]. Livestock disease is the major constraints of productivity causing economic losses in Ethiopia by hundreds of millions of birr annually [5]. Because livestock are the chief sources of cash income to small holders, up to $88 \%$ in the highland livestock-cropping system, diseases are an important cause of reduced productivity of meat and milk as well as draft, hides and dung fuel [6]. Domestic animals are often afflicted with various skin problems, some easy to cure others more complicated, and some even highly contagious to the human handlers.
Lumpy Skin Disease also called Pseudo urticaria, Neethling Virus Disease, Exanthema Nodularis Bovis, Knopvelsiekte is one of the most economically significant transboundary, emerging a viral disease that affects cattle of all ages and breeds. It is classifed as one of diseases Notifiable to the OIE List A disease caused by a virus of the family Poxviridae, genus Capripoxvirus, and species LSDV, which antigenically closely related to sheep and goat poxviruses [7].

The transmission of LSDV is believed to occur mainly by blood-feeding arthropods vectors including hard ticks, biting flies and mosquitoes [8]. LSD is usually diagnosed based on characteristic clinical signs, epidemiology, histopathology, virus isolation and PCR [9]. It is an acute to chronic infectious viral disease characterized by fever, nodules on the skin, mucous membranes and internal organs, high morbidity, low mortality, emaciation, enlarged lymph nodes, edema of leg and brisket, mastitis and orchitis and sometimes death [10]. The major epidemic outbreak of LSD has occurred in different regions of Ethiopia. Now it spreads to almost all regions and agroecological zones of the country. It is one of the most economically important livestock diseases in the country. It's common at the 
end of summer and beginning of autumn season in the country [11].

It causes significant economic impacts as a result of reduced milk production, temporary or permanent sterility, deaths, beef loss, loss of draft animals' power, abortion, loss of condition and damage to the hide. There is no antibiotic treatment for LSD, but supportive treatment can be available. Ring vaccination, quarantine, movement and insect vectors control, are the major control and prevention strategies for LSD [12]. To effectively control LSDV in endemic countries, a comprehensive understanding of the ecology of different bloodfeeding and biting arthropod species in the cattle farming setting is important [13].

In Ethiopia limited works has been done on this disease so far and few works have been reported on risk factors assessments, epidemiological aspects, seroprevalence and financial impacts of LSD and there is lack of information regarding importance the with considering it as simple wound skin disease. Good understanding of epidemiological aspects of LSD related to pathogen, host and environment might aid for control and prevention mechanisms has profound important in country such as Ethiopia [11].

Therefore, the aim of this seminar paper is to review: Epidemiological aspects of lumpy skin disease and its economic impacts.

\section{Literature Review}

\section{Historical Background of Lumpy Skin Disease}

Lumpy skin disease was first seen in Zambia in 1929, and at that time it was considered as it was caused by either plant poisoning or an allergic response of insect bite. The disease was spreaded to other African countries and expanded to Middle East region [12]. Then, 15 years later it was observed from Zambia to Botswana and South Africa, where it affected over eight million cattle causing major economic loss. In 1957 it entered Kenya, associated with an outbreak of sheep pox. In 1970 LSD spreads north into the Sudan, by 1974 it had spread west as far as Nigeria, and in 1977 was reported from Mauritania, Mali, Ghana and Liberia [7].

Another epidemic of LSD between 1981 and 1986 affected Tanzania, Kenya, Zimbabwe, Somalia, Cameroon, and Ethiopia with reported mortality rates in affected cattle of $20 \%$. In subsequent years, Bahrain, Kuwait, Oman, Yemen, and Israel were reported. Until 1989, LSD occurrence was restricted to subSaharan Africa, but Egypt reported its first LSD outbreak in 1988 and Israel in 1989 [7].

\section{Etiology}

LSD is caused by Lumpy Skin Disease virus (LSDV), which is a member of family Poxviridae, subfamily Chordopoxvirinae, genus capripoxvirus, the prototype strain Neethling Virus. LSDV is pleomorphic, enveloped, brick- or oval-shaped dsDNA virus with a molecular size of $350 * 300 \mathrm{~nm}$ and a molecular weight 73 to $91 \mathrm{KDa}$. An LSDV genome sequence is 145 to 152 . The terminal genomic sequences contain a unique complement of at least 34 genes which are responsible in viral virulence, host range and/ or immune evasion of host [14].

\section{Epidemiology}

Lumpy skin disease is an important, economically devastating, notifiable disease which brought production loss in cattle due to generalized malaises and chronic debility [12]. Good understanding of epidemiological aspects of LSD related to pathogen, host and environment might aid for control and prevention mechanisms. Emphasis should be given to exposure of hosts to pathogen in suitable environment that facilitate transmission and distribution of the disease. LSD is more prevalent during the wet summer and autumn months and occurs particularly in low lying areas and along water courses [7].

\section{Geographic distribution}

The geographic coverage of LSD has extended its range to include all countries in sub-Saharan Africa as well as Madagascar and it is endemic to all most all African country and occurs in various ecological zones except Libya, Algeria, Morocco and Tunisia which are still considered as free of the disease. Outbreaks outside the African continent have occurred in the Middle East in 2006 and 2007, in Mauritius in 2008, and Israel has reported with LSD outbreaks. Epidemiological trend of LSD suggests that it is currently endemic in most of African countries and spreading further in to North Africa, Middle East countries and Mediterranean regions because of global trade movement in animals and animal products.

\section{Source of Infection}

Clinically sick animals are the main source of infection to other healthy animals. However, LSD virus can be present in blood, cutaneous lesions, saliva, nasal discharge, lachrymal secretions, milk, semen and feeding and drinking trough, which may be sources for transmission [15-17].

\section{Mechanism of Transmission}

The most likely way for LSD to enter a new area is by introduction of infected animals. Extensive livestock production system allows maximum chance for different herd mixing during utilization of communal grazing lands and watering points. Under this prevailing system it is likely to speculate that the introduction and spread of LSD infection could have favorable environment. Uncontrolled cattle movements due to trade, pastoralism, vector insect's population and dynamic, wet climate which favors insect multiplications and other reasons of cattle movement from place to place could render potential risk factors for the transmission of the disease from herd to herd and from place to place [18]. 
Direct transmission can occur when the animals share the same feeding and drinking trough due to contamination by nasal and salivary discharges from infected animals or ingestion of the already contaminated food or by iatrogenic agents [19]. Suckling calves may be infected through infected milk. Transmission of LSDV through semen has been experimentally demonstrated [20]. A more recent study demonstrated the persistence of the live virus in bovine semen for up to 42 days post infection and viral DNA was detected until 159 days post infection [16].

There is an assumption that virus is also secreted in vaginal secretions. Generally, transmission of the virus by contact is inefficient and field evidence reported that the disease is not contagious [21]. The transmission of LSDV occurs mechanically by blood-feeding biting arthropods vectors including hard ticks, biting flies and mosquitoes [22]. This vector related transmission is apparently mechanical, rather than biological. This distinction is important because infectious organisms do not generally survive in vectors for long periods for multiplication. In the mechanical mode of transmission, the virus is transmitted via contaminated mouth parts of vectors without actual replication of the virus in arthropod cells or tissues. The virus can survive 2-6 days post feeding from infected cattle and transfers this to susceptible cattle by female mosquito, Aedes egypti during experimental infection.

Recently, new evidence has been published reporting a possible role of hard ticks in the transmission of LSDV. The study showed molecular evidence of transstadial and transovarian transmission of LSD virus by Boophilus decoloratus and mechanical transmission by Repicephalus appendiculatus and Ambyloma hebraeum. Mosquitoes (female Aedes egypti and Culex quinquefasciatus) and other flies such as tabanids (horse flies), biting midges (Culicoides nubeculosus), and Glossina species like tsetse fly are among the other arthropod vectors that play a great role in the transmission of the virus. Non biting flies, including housefly (Muscidae), bush fly (Hippoboscidae) and blowflies (Calliphoridae) are also very commonly associated with sucking of infected lachrymal, nasal or other secretions and transfer the virus to another susceptible animal. Vermin, predators and wild birds might also act as mechanical carriers of the virus [23].

Epidemiological evidence suggests, outbreaks of LSD is highly associated with prevalence of high insect vectors population and with upcoming of rainy season. Epidemics of LSD are associated with rainy seasons, river basins and ponds during which cattle grazed and humid areas that is conducive to insect multiplication [7].

\section{Risk Factors}

Host Risk Factors: Lumpy skin disease is a disease of cattle and causes several disorders. Though all breeds and age group are susceptible, Bos Taurus is particularly more susceptible to clinical disease than zebu cattle and Bos indicus. Among Bos
Taurus, fine-skinned, high-producing dairy Channel Island breeds are highly susceptible to LSDV. It is not known that genetic factors influence the disease severity [24]. Young animals are severely affected, and clinical symptoms are rapid to appear. But traditional calf management practices that segregate calves from the herd might have contributed to a decreased exposure risk of calves to the source of infection. Calves in the endemic area can obtain certain protective passive immunity from their dam. An animal recently recovered from an attack is not susceptible to LSDV because there is a solid immunity lasting for about 3 months.

Lactating cows appearing to be severely affected and result in a sharp drop in milk production because of high fever caused by viral infection itself and secondary bacterial mastitis [25]. In local zebu cattle, male animals have higher cumulative incidence than females due to stress factor of exhaustion and fatigue rather than to a biological reason. Most male animals are draft oxen used for heavy labor, which might contribute to an increase in susceptibility. Another reason is that draft oxen cannot protect themselves well from biting flies when harnessed in the yoke, and the beat scratches on their skin induced while plowing may attract biting flies potentially capable of transmitting LSD infection. Generally clinical severity of disease depends on susceptibility, immunological status, and age of the host population and dose and route of virus inoculation [26].

Pathogen Risk Factors: Lumpy skin disease virus is one of the species of capripoxviruses affecting cattle of different breeds and this virus is resistant to different chemical and physical agents [27]. The virus can persist for about 33 days in necrotic skins and at ambient temperature. It can survive in a wet environment which can protect them from rays of sun light [28]. The virus is present in nasal, lachrymal and pharyngeal secretions, semen, milk and blood and it may remain in saliva for up to 11 days and in semen for 22 days [29]. There is no evidence of the virus persisting in meat of infected animals, but it might be isolated from milk in early stages of fever. The virus may persist for months in lesions in cattle hides. LSD virus may persist for 6 months on fomites, including clothing and equipment but there is no evidence that virus can survive more than four days in insect vectors [30].

Environmental Risk Factors: Environmental determinants play a great role in the epidemiology of lumpy skin disease. It had major impact on the agent, host and vectors as well as interaction between them. High ambient temperatures, farming practices and cow which produce high milk yields, could be deemed to stress the animals and contribute to the severity of the disease in Holstein-Friesian cattle [31]. LSD is associated with increased number of insects which are mechanical vectors. It is more prevalent during the wet and warmer condition of summer and autumn months and occurs particularly in low lying agro-climate zone and along watercourses [7]. The warm and humid climate in midland and lowland agro-climates has been 
considered as more favorable environment for the occurrence of large populations of biting flies than the cool temperature in the highlands [32].

These predisposing factors have a great role in maintenance of arthropod vector and transmission of the virus to susceptible animals [33]. Animals share the same grazing and watering points and unrestricted movement of animals across different borders following rainfall were some of the factors [34].

\section{Morbidity and mortality}

The morbidity of the disease is highest in wet, warm weather and decreases during the dry season [35]. In outbreaks of the disease, the morbidity rate varies widely depending on the immune status of the hosts and the abundance of mechanical arthropod vectors and averagely ranges from $3 \%$ to $85 \%$. But it can reach as high as $100 \%$ in natural outbreaks while mortality rate rarely exceeds $5 \%$ but may sometimes reach $40 \%$.

\section{Pathogenesis}

Lumpy skin disease is developed by entry of infectious LSDV through skin or GIT mucosa then viremia accompanied by a febrile reaction [36]. Then the virus reaches and causes swelling of regional lymph nodes. Mechanism by which the virus causes skin lesions is due to replication of the virus in specific cell such as endothelial cells of lymphatic and blood vessels walls with development of inflammatory nodules on skin [36]. Lumpy skin disease is generalized and epitheliotrophic disease that cause localized and systemic reaction and results in vasculitis and lymphadenitis which result in to oedema and necrosis. In some severe cases thrombosis and other symptoms will be observed. Nodules of LSD may be changed to grey-pink with caseous necrotic cores. Circumscribed necrotic lesions may ulcerate. Skin localization is due to epitheliotrophic property of LSDV [37].

Lumpy skin disease skin nodules may exude serum initially but develop a characteristic inverted grayish pink conical zone of necrosis. Adjacent tissue exhibits congestion, hemorrhages and edema. Enlarged lymph nodes are found and secondary bacterial infections are common within the necrotic cores [38]. Multiple virus-encoded factors are produced during infection, which influence pathogenesis and disease.

\section{Clinical Sign}

Incubation period of LSD can vary under field and experimental conditions. It varies from 4 and 14 days in experimentally inoculated animals and 2-4 weeks in naturally infected animals. Course of lumpy skin disease may be acute, sub-acute and chronic [39]. The most common sites of nodules are head, neck, perineum, genitalia, limb and udder; involve skin, cutaneous tissues and sometime underlying part of the muscle. Severity of clinical signs depends on strain of Capripoxvirus and breed of the host cattle and in case of experimental infection route of transmission and dose of the virus also has determinant factor.
The virus causes from unapparent infection to severe clinical symptoms and those animals which develop clinical disease may have a biphasic febrile reaction. The major visible clinical signs are; fever of 40-41.5oC which may last 6-72 hours, lachyrimation, increased nasal and pharyngeal secretion, loss of appetite, reduced milk production, some depression and movement reluctance, nodule in the skin, mucous membrane and internal organs and swelling of superficial lymph nodes. Diameter of nodular lesion may be up to 1-7 cm diameter appears as round, firm, intradermal and circumscribed areas of erected hair.

In severe cases, ulcerative lesions may develop in mucous membrane of mouth, trachea, and larynx and esophagus. The necrotic cores become separated from the adjacent skin and are referred to as 'sit-fasts'. It might be exacerbated by Secondary bacterial complication and infestation of fly worms. Lesions in skin, subcutaneous tissue, and muscles of limbs, together with severe skin inflammation caused by secondary infection of lesions, greatly reduce mobility.

\section{Diagnosis}

Lumpy skin disease can be diagnosed based on epidemiology, clinical signs, necropsy findings and laboratory diagnose. Clinically it is diagnosed by its pathognomic nodular lesions like multiple skin nodules with circumscribed areas of erected hair, nodules around nostrils, turbinate, mouth, vulva and prepuce that can persist as hard lumps or become moist, necrotic and slough. Also, there is edema of leg and swelling of the superficial lymph nodes.

At necropsy, LSD can be diagnosed by looking at the nodules on the skin, in mouth, nostrils, vulva and prepuce and, on mucous membranes, swelling of the superficial lymph nodes and systemic involved symptoms. Rapid laboratory diagnoses are needed to confirm the disease. Laboratory diagnosis of LSD can be made by transmission electro microscopic isolation and identification of the agent, Serological tests, routine histopathological examination and immune histological staining.

All capripoxviruses grow slowly on cell cultures and may require several passages. They can be recognizable by cytopathic effects. In addition, the virus can be propagated in the chorioallantoic membranes of embryonated chicken eggs, causing macroscopic pock lesions. The replication of LSDV occurs in the cytoplasm of the host cell resulting in intracytoplasmic eosinophilic inclusion bodies [40]. Isolation of virus can be made from collected biopsy or at post-mortem from skin nodules, lung lesions or lymph nodes within the first week of the occurrence of clinical signs, before the development of neutralizing antibodies.

Primary cell cultures are bovine skin dermis and equine lung cells, but growth of such viruses is slow and requires several passages. Serological tests are used for retrospective confirmation of lumpy skin disease, but they are much more time consuming to be used as primary diagnostic methods and 
limited presence of detectable antibodies in serum [36]. Realtime PCR for the diagnosis of LSD has high sensitivity and good specificity and it is most appropriate technique.

\section{Control and Prevention}

\section{Treatment}

There is no specific antiviral treatment available for LSD infected cattle. Sick animals may be removed from the herd and given supportive treatment consisting of local wound dressing to discourage fly from worry and prevent secondary infections.

\section{Control and Prevention}

In Endemic Areas: Control and prevention of LSD in endemic countries like Ethiopia relies mainly on vaccination of cattle above six months every year. Because calves born to immunized cows will have passive immunity that persists for about six months. The experience in the major parts of the country showed that the vaccination approach is commonly chosen and is often that of ring vaccination around a local foci outbreak when it occurs.

Four live attenuated strains of capripoxvirus are currently used as vaccines to control LSD; these include the Kenyan sheep- and goat-pox strain (KS-1), the Yugoslavian RM 65 sheep-pox strain, the Romanian sheep-pox strain and the South African neethling LSDV strain. Two different vaccines have been widely and successfully used for the prevention of LSD in cattle populations in Africa. In southern Africa, the Neethling strain of LSD was passaged 50 times in tissue cultures of lamb kidney cells and then 20 times in embryonated eggs. It is produced in tissue culture and issued as a freeze-dried product. In Kenya, strain of sheep and goat pox virus was passaged 16 times in pre-pubertal lamb testes or fetal muscle cell cultures. Mostly Neethling strain vaccine is used to vaccinate cattle in Africa.

Because of antigenic homology and cross-protection between sheep pox, goat pox and LSD viruses, any of these viruses can be used as a vaccine strain to protect cattle against LSDV. Animals that have recovered from natural infection or vaccinated with one of the strains have lifelong protection and are resistant to infection with any other strain and do not become carrier). Protective immunity will develop from 10 to 21 days post vaccination, and then require an annual booster dose.

Lumpy skin disease virus is susceptible to sun light and detergents containing lipid solvents like ether (20\%), chloroform, formalin (1\%) and phenol (2\%). The virus could be inactivated after heating for 1 hour at $55^{\circ} \mathrm{C}$. However, it withstands drying, $\mathrm{pH}$ changes, if not an extreme $\mathrm{pH}$ and can remain viable for months in dark room such as infected animal shade off its host. LSDV can persist in skin plugs for about 42 days.

In New Areas: Risks of introduction of the disease in to the new areas are by the introduction of infected animals and animals' products and contaminated materials. If the occurrence of LSD is confirmed in new areas, before the spread of the disease to other areas extensively, quarantine of the area, slaughtering of the diseased and in contact animals and contacted equipments must be cleaned and disinfected. Proper disposal of infected animal and animal products to remove the source of infection, Quarantine and movement controls of animals; products and other potentially infected items to prevent spread of infection; Control of insect vectors to minimize mechanical transmission of the virus, by insect repellent, insect-proof housing for animals, and application of insecticides; Tracing and surveillance to determine the source and extent of infection and Ring vaccination are the major control and prevention strategies of Lumpy Skin Disease [41].

\section{Status of Lumpy Skin Disease in Ethiopia}

In Ethiopia lumpy skin disease was first observed in the northwestern part of the country (southwest of Lake Tana) in 1983 [42]. After its first appearance, an explosive sudden epidemic spread from the north through the central to the southern part of the country. LSD is one of reported diseases in Ethiopia which deserves outbreak notification to the National veterinary services. The national disease report showed LSD has spread virtually to all the regions in the country and in different agro-climatic zones. Because of the wide distribution of the disease and the size and structure of the cattle population in Ethiopia, LSD is one of the most economically important livestock diseases in the country.

Across different agro-ecological zones in Ethiopia an overall observed LSD prevalence is $8.1 \%$ and a mortality of $2.12 \%$. The case fatality is estimated to be $2 \%$. The highest frequency of LSD outbreaks in the country have been reported between September and December, with the highest numbers in October and November; which is the end of the main rainy season in most parts of the midland and highland agro-ecological zones and the lowest number is reported in May [43]. Among indigenous local zebu cattle Fogera breed located in the northwest of the Ethiopia is reported to manifest severe clinical disease in epizootic occurrence of LSD. A study in Ethiopia also shows that communal grazing, watering points and movement of infected stock have been found to be associated with the occurrence of LSD.

Lumpy skin disease is reported from all regions of the country. The majority of outbreaks are frequently reported from midland agro-climate zone of Oromia, Amhara and the Southern Nations, Nationalities and People's Region, which is known to be favorable for the breeding of the blood feeding insect vectors of LSD and has the highest population density of livestock in Ethiopia.

\section{Economic Importance of Lumpy Skin Disease}

Major consequences of the disease are retarded genetic improvement, inability of the animal to work, draught power and traction loss due to lameness, decreased milk production, abortion, infertility, chronic debility in beef cattle and loss of condition and damaged hides cause enormous economic losses. Lumpy skin disease is one of the economically significant 
diseases in Africa and the Middle East countries that cause severe production loss in cattle. The economic importance of the disease is mainly due to having high morbidity rate rather than mortality.

The impact of lumpy skin disease can broadly be divided into direct losses, i.e. the direct impact on animal health and productivity, and indirect losses. Direct losses include visible losses such as animal death and illness or stunting that result from disease or subsequent control methods. Indirect losses, on the other hand, include less immediate impacts of animal disease, such as reduced productivity or changes in herd fertility but, ban from international trade of livestock, mitigation and control costs, losses in consumer confidence and negative effects on other sectors of the economy.

In resource-limited countries, the slaughter of infected and in-contact animals is usually seen as a waste of a valuable source of food and is not usually feasible. This kind of loss primarily affects the stakeholders of the agriculture sector, for example farmers. Annual financial loss following an LSD outbreak in Ethiopia is calculated as the sum of the values of the annual production losses due to morbidity and mortality and the costs for treatment and vaccination. Treatment cost represents the expenses incurred by farmers for medication.

Lumpy Skin Disease incidence interferes with normal herd dynamics, causing a reduction of surplus in the case of mortality, or a reduction of stock for the market in affected herds because of long term morbidity that can lower weight gain. The valuation of the draft power loss depends on the point in the crop season that an ox fell sick and on the corresponding demand for draft power during that specific season $[44,45]$. The reduced work output of draft oxen due to LSD is an important loss for the mixed crop-livestock farming system. Morbidity of draft oxen leads to reduce crop production through a reduction in cultivation and lower yields due to inefficient land preparation and timing. Permanent damage to the skin and hide greatly affect leather industry. It causes ban on international trade of livestock and causes prolonged economic loss as it became endemic and brought serious stock loss.

The financial loss impact between local zebu and HF/ crossbreds shows that HF/crossbreds have far higher production losses in most parameters compared with local zebu cattle; the financial loss impact thus has a linear relationship with the incidence of the disease in each breed type. Milk production losses of up to $50 \%$ per lactation have been reported in infected herd [46]. This shows that LSD infection is very important in high producing exotic breeds. Overall, LSD is considered as a disease of high economic pressure because of its ability to compromise food security through protein loss, draft power, reduced output of animal production, increase production costs due to increased costs of disease control, disrupt livestock and their product trade, result of reduced milk yield, weight loss, abortion, infertility in cows, mastitis and infertility in lactating cows, infertility in bulls.

\section{Conclusion and Recommendation}

Lumpy skin disease is one of the most economically significant transboundary, emerging viral diseases of domestic cattle caused by viruses of the genus Capripoxvirus. It has significant economic importance in animals, due to chronic debility, reduction in milk production and weight, damaged hides, abortion and death. LSD is now endemic in most African and Middle Eastern countries. LSDV transmission among cattle is by the mechanical haematophagus arthropod vectors [47]. The importance of different mechanical vectors in the transmission of LSDV is likely to vary in different geographical regions, depending on the environment, temperature, humidity and abundance of the vectors. LSD is common during wet season that is at the end of summer and beginning of autumn. The control of LSD can be achieved through vaccination, restriction of animal movement and eradication of infected and exposed animals.

Based upon the above conclusion, the following recommendations are forwarded;

a. The government and Non-government organization should facilitate awareness creation and training for farmers in recognizing the disease

b. If LSD entered the disease-free country, rapid detection and prompt culling of infected herds, and carcasses and ring vaccination should be considered.

c. Animals suspected with LSD should be isolated and the farm should be quarantined until definitive diagnosis is determined.

\section{Acknowledgement}

First, I would like to thank my Almighty God for keeping me healthy and helping success of my life. I am greatly indebted to my advisor Dr. Feyisa Bekuma for his close intellectual advice, and devotion of his time to correct and edit this seminar paper. I wish to record my sincere appreciation to Dr. Gezail Abafaji, who is course coordinator for his untiring effort on properly planning the course schedule in the logical manner and giving us important training and orientation how to deliver lecture and on the way to write seminar.

Next, I would like to express my sincerely thanks to all my classmates and close friends who shared me love and experience. Lastly but not least, I would like to extend my deepest gratitude to my lovely family for their financial and moral support.

\section{References}

1. Gebreegziabhare B (2010) An over view of the role of Ethiopian livestock in livelihood and Food safety. Ethiopia.

2. Central Statistical Agency (CSA) (2011) Agricultural sample survey vol; 2, statistical agency Federal Democratic Republic of Ethiopia. Addis Ababa, Ethiopia.

3. Azage T, Alemu G (1997) Prospects for peri-urban dairy development in Ethiopia. In Proceedings of the Fifth National Conference of the Ethiopian Society of Animal Production. Addis Ababa, Ethiopia, p. 2839. 
4. Jahnke H (1982) Livestock production systems and livestock development in Tropical Africa. Kieler Wissenchaffsverlag Vauk, Federal Republic of Germany pp. 253.

5. Sintayehu Y, Fekadu B, Azage T (2008) Dairy production, processing and marketing system of Shashemene-Dilla area, south, Ethiopia. Improving productivity and market success of Ethiopian farmers. project. International Livestock Research Institute, Addis Ababa, Ethiopia.

6. Rashid M, Shank R (1994) United Nations development programmed emergencies unit for Ethiopia technical report: rough guide to animal diseases in Ethiopia.

7. OIE (2010) OIE Manual of Diagnostic Tests and Vaccines for Terrestrial Animals. Lumpy skin disease. pp. 768-778.

8. Chihota CM, Rennie LF, Kitching RP, Mellor PS (2001) Mechanical transmission of lumpy skin disease virus by Aedes aegypti (Diptera. Culicidae). Epidemiol Infect 126(2): 317-321.

9. Tuppurainen ESM, Oura CAL (2012) Review: Lumpy Skin Disease: An Emerging Threat to Europe, the Middle East and Asia. Tran boundary and Emerging Diseases 59(1): 40-48.

10. Radostits OM, Gay CC, Hinchcliff KW, Constable PD (2007) Veterinary Medicine: A textbook of diseases of cattle, horses, sheep, pigs and goat $\left(10^{\text {th }} \mathrm{edn}\right)$, WB Saunders Co, Philadelphia, USA.

11. Gari G, Bonnet P, Roger F, Waret-Szkuta A (2011) Epidemiological Aspects and Financial Impact of Lumpy Skin Disease in Ethiopia. (NAHDIC), Preventive Veterinary Medicine 102(2): 274-283.

12. Tuppurainen ESM, Oura CAL (2011) Review: Lumpy Skin Disease: An Emerging Threat to Europe. the Middle East and Asia, Institute for Animal Health, Pirbright, Surrey, UK.

13. Brenner J, Haimovitz M, Oron E, Stram Y, Fridgut O, et al. (2006) Lumpy skin disease (LSD) in large dairy herd in Israel. Israel Journal of Veterinary Medicine 61: 73-77.

14. Kara PD, Afonso CL, Wallace DB, Kutish GF, Abolnik C, et al. (2003) Comparative sequence analysis of the South African Vaccine strain and two virulent field isolates of Lumpy Skin Disease Virus. Archives of Virology 148(7): 1335-1356.

15. Babiuk S, Bowden T, Parkyn G, Dalman B, Manning L, et al. (2008) Quantification of Lumpy skin disease virus following experimental infection in cattle. Transboundary and Emerging diseases 55(7): 299307

16. Irons PC, Tuppurainen ESM, Venter EH (2005) Excretion of the lumpy skin disease virus in bull semen. MSc dissertation pp. 63(5): 12901297.

17. Zelalem Abera, Hailu Degefu, Getachew Gari, Zelalem Ayana (2015) Review on Epidemiology and Economic Importance of Lumpy Skin Disease.

18. Toma B, Dufour B, Sanaa M, Be'net JJ, Moutou F, et al. (1999) Applied Veterinary Epidemiology and the Control of Disease in Populations.

19. Lefèvre PC, Gourreau JM (2010) Lumpy Skin disease. Lavoisier, Paris, France, pp. 393-407.

20. Annandale CH, Holm DE, Ebersohn K, Venter EH (2013) Seminal Transmission of Lumpy Skin Disease Virus in Heifers. Transboundary and emerging diseases 61: 443-8.

21. Salib FA, Osman AH (2011) Incidence of lumpy skin disease among Egyptian cattle in Giza Governorate, Egypt, Veterinary World 4(4): 162-167.

22. Magori-cohen R, Louzoun Y, Herziger Y, Oron E, Arazi A, et al. (2012) Mathematical modeling and evaluation of the different routes of transmission of lumpy skin disease virus. Veterinary Research 43:1.
23. Animal Health Australia (2009) Disease strategy: Lumpy skin disease (Version 3.0). Australian Veterinary Emergency Plan (AUSVETPLAN), Edition 3, Primary Industries Ministerial Council, Canberra ACT 3: 42.

24. Babiuk S, Bowden T, Boyle D, Wallace D, Kitching RP (2008) Capri poxviruses: an emerging worldwide threat to sheep goats and cattle. Transboundary and Emerging Diseases 55(7): 263-272.

25. Ali AA, Esmat M, Attia H, Selim A, Abdel-hamid YM (1990) Clinical and Pathological Studies of on the lumpy skin disease in Egypt. The veterinary record 127(22): 549-550.

26. Center for Food Security and Public Health (CFSPH) (2008) The Center for Food Security and Public Health, Iowa State University. College of Veterinary Medicine and Institution of International cooperation in Animal Biologics, an OIE.

27. Murphy FA, Gibbs EPJ, Horzinek MC, Studdert MJ (1999) Veterinary Virology. Pox viridae, ( ${ }^{\text {rd }}$ edn), California, USA, pp. 277-292.

28. Weiss WE (1968) Lumpy Skin disease. In Emerging Diseases of Animals.

29. Barnard BHJ, Munz E, Dumbell K, Prozyesky L (1994) Lumpy skin disease. In: Infectous disease of livestockwith special reference to South Africa 1: 604-612.

30. Davies FG (1991) Lumpy skin disease, an African capripox virus disease of cattle. Br Veterinary Journal 147(6): 489-503.

31. Tageldin MH, Wallace DB, Gerdes GH, Putterill JF, Greyling RR, et al. (2014) Lumpy skin disease of cattle: an emerging problem in the Sultanate of Oman. Tropical Animal Health and Production 46: 241246.

32. Tuppurainen ESM, Lubinga JC, Stoltsz WH, Troskie M, Carpenter ST et al. (2013) Mechanical transmission of lumpy skin disease virus by Rhipicephalus appendiculatus male ticks. Epidemiology and infection 141(2): 425-430.

33. Thomas L (2002) Lumpy-skin disease, a disease of socioeconomic importance.

34. Yeruham I, Nir O, Braverman Y, Davidson M, Grinstein H, et al. (1995) Spread of Lumpy skin disease in Israel dairy herds. The Veterinary record 137(4): 91-93.

35. OIE (2008) Lumpy Skin Disease (Neethling, Knopvelsiekte): A technical Report. The Centre for Food Security and Public Health, Iowa State University.

36. Vorster JH, Mapham PH (2008) Lumpy skin disease, Livestock health and Production review.

37. Gari G, A Waret-Szkuta, Grosbois V, Jacquiet P, Roger F (2010) Risk factors associated with observed clinical lumpy skin disease in Ethiopia. Epidemiol Infect 138(11): 1657-1666.

38. Gari G, Grosbois V, Waret-Szkuta A, Babiuk S, Jacquiet Pet al. (2012) Lumpy skin disease in Ethiopia: seroprevalence study across different agroclimate zones. Acta trop 123(2): 101-106

39. Gari G, Waret-Szkuta A, Grosbois V, Jacquite P (2010) Risk Factors Associated with observed clinical lumpy skin disease in Ethiopia. PhD thesis, Ethiopia 138(11): 1657-1666.

40. EFSA AHAW Panel (EFSA Panel on Animal Health and Welfare) (2015) Scientific Opinion on lumpy skin disease. EFSA Journal 13(1): 3986.

41. Babiuk S, Wallace D, Smith S, Bowden T, Dalman B, et al. (2009) Detection of Antibodies against Capri poxviruses using an inactivated Sheep pox virus ELISA. Transboundary and Emerging Diseases 56(4): 132-141.

42. Mebratu G, Kassa B, Fikre Y, Berhanu B (1984) Observations on the outbreak of lumpy skin disease in Ethiopia. Vet Tropicaux 37(4): 395399. 
43. Gizachew A, Haftu R, Jemberie S, Belay A, Gelaye E, et al. (2014) Lumpy skin disease in cattle in central Ethiopia: outbreak investigation and isolation and molecular detection of lumpy skin disease virus. Rev sci tech Off int Epiz 33(3): 877-887.

44. Ahmed W, Zaher KS (2008) Observations on lumpy skin disease in local Egyptian cows with emphasis on its impact on ovarian function. African Journal of Microbiology Research 2: 252-257.
45. Bruce F, Eldridge, Edman JD (2004) Medical Entomology: A Textbook on Public Health and Veterinary Problems Caused by Arthropods. Capripox viruses Lumpy skin disease pp. 488.

46. Kitching R (2003) Vaccines for lumpy skin disease, sheep pox and goat pox. Dev Biol (Basel) 114: 161-167.

47. Thornton PK (2010) Livestock production: recent trends, prospects. The Royal Society 365(1554): 2853-2867.

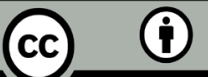

This work is licensed under Creative

Commons Attribution 4.0 License

DOI: 10.19080/JDVS.2018.07.555716

\section{Your next submission with Juniper Publishers will reach you the below assets}

- Quality Editorial service

- Swift Peer Review

- Reprints availability

- E-prints Service

- Manuscript Podcast for convenient understanding

- Global attainment for your research

- Manuscript accessibility in different formats

(Pdf, E-pub, Full Text, Audio)

- Unceasing customer service

Track the below URL for one-step submission https://juniperpublishers.com/online-submission.php 